\title{
Predictors of contrast-induced acute kidney injury in patients with coronary artery disease receiving contrast agents twice within 30 days
}

Chong-Huai Gu ${ }^{1,2+}$, Xiao-Zeng Wang ${ }^{1+}$, Ya-Ling Han ${ }^{1}$, Quan-Min Jing ${ }^{1}$, Li-Li Ren ${ }^{1}$, Yan Zhang ${ }^{1}$, Jun-Yin Peng ${ }^{1}$ and Xin Zhao ${ }^{1 *}$

\begin{abstract}
Background: None of study mentioned about contrast-induced acute kidney injury (Cl-AKI) in people who have received contrast agents twice within in a short period of time. This study is trying to identify the predictors.

Methods: We enrolled 607 patients between Oct. 2010 and Jul. 2015 who received contrast agents twice within 30 days in the Department of Cardiology of the General Hospital of Shenyang Military Region. The primary outcome was $\mathrm{Cl}$-AKI within $72 \mathrm{~h}$ after contrast agent exposure. Patients were divided into groups $\mathrm{A}(n=559)$ and group $\mathrm{B}$ $(n=48)$ according to whether Cl-AKI occurred after the second agent.

Results: Patients in group B (Cl-AKI occurred after the second agent) had a more rapid heart rate and more usage of diuretics and digitalis. In group B, Cl-AKI occurred more frequently after the first agent. Multivariate logistic regression showed that diuretic $(P=0.006)$ and intra-aortic balloon pump (IABP) usage $(P=0.012)$ were independent predictors of $\mathrm{Cl}$-AKI after the first agent. Angiotensin-converting enzyme inhibitor/Angiotensin II receptor antagonist (ACEI/ARB) usage $(P=0.039)$, IABP usage $(P=0.040)$ and $\mathrm{Cl}$-AKI occurring after administration of the first agent $(P=0.015)$ were independent predictors of $\mathrm{Cl}-\mathrm{AKI}$ after the second. Furthermore, dividing the patients into tertiles of the time interval between the two agents showed that CI-AKI occurred more frequently when the second agent was administered within 1-3 days after the first exposure than within $4-6$ days (12.4\% vs. $5.0 \%, P=0.008)$ or $\geq 7$ days $(12.4 \%$ vs. $6.4 \%, P=0.039)$.

Conclusions: Diuretic and IABP usage are independent predictors of $\mathrm{CI}$-AKI following exposure to a first contrast agent. The major predictors of $\mathrm{Cl}-\mathrm{AKI}$ after exposure to a second agent are time since the first contrast exposure, ACEI/ARB usage, and IABP usage. More importantly, a three-day interval between the two agents is associated with a higher incidence of $\mathrm{Cl}-\mathrm{AKI}$ following the second administration.
\end{abstract}

Keywords: Predictors, Contrast-induced acute kidney injury, Coronary artery disease

\footnotetext{
* Correspondence: zhaoxin81830@sina.com

${ }^{\dagger}$ Chong-Huai Gu and Xiao-Zeng Wang contributed equally to this work.

${ }^{1}$ Cardiovascular Research Institute and Department of Cardiology, General Hospital of Shenyang Military Region, Shenyang 110840, China

Full list of author information is available at the end of the article
} 


\section{Background}

Contrast-induced acute kidney injury (CI-AKI) is a familiar complication experienced by patients with coronary artery disease (CAD) who are administered iodinecontaining contrast agents for procedures such as coronary angiography (CAG) and percutaneous coronary intervention (PCI) [1-3].

CI-AKI has been proven to be associated with risk indices of longer hospitalization and short- and/or longterm mortality $[2,4,5]$. The incidence of CI-AKI is approximately $0.6-2.3 \%$ [6]. However, this value varies depending on the presence of risk factors, and several clinical predictors of CI-AKI have been introduced [7, 8]. Additionally, CI-AKI has been linked with a worse clinical outcome in patients with acute coronary syndrome (ACS) [5, 8-10]. Well-established risk factors of $\mathrm{CI}$-AKI include diabetes, congestive heart failure, acute hypotension, advanced age, ST-elevation myocardial infarction (STEMI), volume depletion, the amount of contrast administered, the type of contrast media, and the simultaneous use of nephrotoxic medications in unselected patients after CAG or PCI [7, 11, 12]. However, those studies mainly focused on the effect of a one-time exposure to a contrast agent on in-hospital or long-term endpoints $[5,8,9]$.

It is becoming more common for patients with CAD to receive a contrast agent two or more times (CAG or $\mathrm{PCI}$ ) because of delay-PCI, rescue-PCI or other reasons. The aim of our investigation was to evaluate predictors of the development of CI-AKI in patients who received contrast agents twice within 30 days and the association between CI-AKI and adverse clinical outcomes.

\section{Methods}

\section{Study population}

This was a single-center, retrospective, observational study. All research adhered to the tenets of the Declaration of Helsinki, and compliance was maintained throughout the study. The subjects were recruited from the cardiovascular catheterization database of the General Hospital of Shenyang Military Region between Oct. 2010 and Jul. 2015. The total number of patients who underwent CAG or PCI was 23,444. Of these patients, 607 received contrast agents twice within a 30-day period. All patients provided written informed consent. All experimental and operational procedures were performed using standard interventional techniques. Cardiogenic shock (CS) patients were excluded. CS is defined below. Patients were divided into two groups according to whether CI-AKI occurred following exposure to the second agent: group A $(n=559)$, no occurrence of CI-AKI following the second agent, and group B ( $n=$ 48), occurrence of CI-AKI following the second agent.

\section{Definitions}

The primary outcome was CI-AKI after any of the contrast agents. CI-AKI was diagnosed based on the Risk, Injury, Failure, Loss of kidney function and End-stage kidney disease/Acute Kidney Injury Network (RIFLE/ AKIN) criteria, which were defined as a serum creatinine level increase of $25 \%$ or creatinine $0.5 \mathrm{mg} / \mathrm{dl}$ or more above baseline within $72 \mathrm{~h}$ after the administration of the contrast agent $[13,14]$. The estimated glomerular filtration rate (eGFR) was calculated using the equation from the Modification of Diet in Renal Disease formula: eGFR $=175 \times$ serum creatinine $e^{-1.154} \times$ age $^{-0.203} \times(0.742$, if female) [15]. Chronic kidney disease (CKD) was defined as an eGFR $<60 \mathrm{ml} /\left(\min \cdot 1.73 \mathrm{~m}^{2}\right)$ for at least 3 months [16]. Serum creatinine was measured before the procedure and daily for 3 days after the administration of the contrast agent. ACS was defined according to the guidelines of the European Society of Cardiology (ESC) [17]. Patients at high risk of CI-AKI after exposure to any of the contrast agents routinely received intravenous hydration treatment with saline solution administered at $1 \mathrm{ml} /$ $(\mathrm{kg} \cdot \mathrm{h})$ for $12 \mathrm{~h}$ after exposure to the contrast agent. Anemia was defined as hemoglobin $(\mathrm{Hb})$ of less than 12 $\mathrm{g} / \mathrm{dl}$ in females and $13 \mathrm{~g} / \mathrm{dl}$ in males according to the World Health Organization's recommendation [18]. Positive cardiac markers at admission were defined as an elevated serum troponin I (cut-off of $0.15 \mathrm{ng} / \mathrm{ml}$ ) and/or a creatine kinase-myocardial band (CK-MB) (cut-off of $24 \mathrm{U} / \mathrm{L}$ ). ST elevation on the admission electrocardiogram (ECG) was defined as recommended by the ESC guidelines [19]. CS was defined as a systolic blood pressure of less than $85 \mathrm{mmHg}$ with evidence of decreased organ perfusion caused by severe left ventricular dysfunction, right ventricular infarction or mechanical complications of the infarction [9].

\section{Statistical analysis}

Continuous variables are presented as the mean \pm standard deviation (SD) or the median, as appropriate, and categorical variables are given as percentages (\%). The $t$ test or Mann-Whitney $U$ test was used to compare continuous variables between two groups, and one-way ANOVA was used to compare categorical variables between groups. The chi-squared test was used to compare the rates of outcomes. Basic data were analyzed by using IBM SPSS version 20.0. Differences in demographic variables were evaluated using the chi-squared test. Nonnormally distributed continuous variables, presented as medians and interquartile ranges, were analyzed using the Wilcoxon rank-sum test. Logistic regression analysis was used to calculate odds ratios for the comparison of CI-AKI rates between groups. Multivariate analysis for CI-AKI included the results with values of $P<0.05$ in the univariate analysis or those that could potentially 
affect the clinical outcome according to our experience. Survival analysis was used to compare patients who developed CI-AKI and those who did not develop CI-AKI following administration of the second agent using the Kaplan-Meier estimator. All $P$ values were two tailed, and statistical significance was defined by a $P$ value $<$ 0.05 .

\section{Results}

The 607 consecutive patients exposed to contrast agents twice within 30 days and who had complete clinical data were separated into two groups (A and B) according to whether CI-AKI occurred following the second exposure. Forty-eight (7.9\%) patients developed CI-AKI after the second administration. Baseline characteristics, laboratory results and medications for the two groups are listed in Table 1. Patients in group B exhibited a faster in-hospital heart rate $(81.4 \pm 17.3$ beat $/ \mathrm{min}$ vs. $76.4 \pm$ 14.1 beat $/ \mathrm{min}, P=0.022$ ). Diuretics $(56.3 \%$ vs. $37.6 \%$, $P=0.011)$ and digitalis $(35.4 \%$ vs. $18.4 \%, P=0.005)$ were also used more frequently in group $B$. The other variables did not differ significantly between the two groups.

A review of the procedural details revealed that there was no significant difference between the two groups in the operative approach or the amount of contrast media used during the procedure. In addition, the number of stent implantations and lesions matched well. Nonetheless, CI-AKI occurred more frequently after exposure to the first contrast agent in group B $(31.3 \%$ vs. $7.3 \%$, $P<0.001$ ). Furthermore, the maximal serum creatinine level was higher in group B than in group A following exposure to the second agent $(100.1 \pm 27.3 \mu \mathrm{mol} / \mathrm{L}$ vs. $76.6 \pm 27.7 \mu \mathrm{mol} / \mathrm{L}, P<0.001$, Table 2 ).

Binary logistic regression was performed to identify predictors of CI-AKI in patients who received a contrast agent twice. In the multivariate regression model, the independent predictors for the occurrence of CI-AKI after the first contrast agent were diuretic $(P=0.006)$ and IABP usage $(P=0.012$, Table 3$)$, while for the second agent, CI-AKI indices from the multivariate regression model revealed that the independent predictors were the time interval between exposure to the two agents $(P=0.037)$, ACEI/ARB usage $(P=0.039)$, IABP usage $(P=0.040)$ and the occurrence of CI-AKI following the first agent $(P=0.015$, Table 4$)$.

We separated patients by tertiles of the interval between the two agents: $1-3$ days, 4-6 days and $\geq 7$ days between exposures. The incidence of CI-AKI following the second agent was significantly higher in the 1-3-day group than $4-6$-day group $(12.4 \%$ vs. $5.0 \%, P=0.008)$ and $\geq 7$ day group ( $12.4 \%$ vs. $6.4 \%, P=0.039$, Fig. 1$)$.

All patients had complete clinical follow-up data. The median follow-up duration was 37 months (interquartile range: 23 to 61). The incidence of all-cause death was similar between the two groups $(3.8 \%$ vs. $4.2 \%$, $P=0.426)$. Total major adverse cardiovascular events (MACE) appeared in $51(9.1 \%)$ group A patients and 6 (12.5\%) group B patients $(P=0.438)$. Among these participants, cardiac death occurred in 22 patients (group A vs. group $\mathrm{B}=3.4 \%$ vs. $4.2 \%, P=0.154$ ) during the followup period. Only 3 patients (group A) had a myocardial infarction during the follow-up period. The incidence of in-stent restenosis was also not significantly different between the two groups (5.0\% vs. $6.3 \%, P=0.728$, Table 5$)$. After adjusting for clinically and statistically relevant covariates, the incidence of MACE and all-cause death was higher in group B, although this difference was not significant (Fig. 2).

\section{Discussion}

In the present study, we aimed to investigate the possible predictors of CI-AKI in patients who received a contrast agent twice within 30 days. The major findings of this study are as follows: 1$)$ diuretic $(P=0.006)$ and IABP usage $(P=0.012)$ were strongly associated with the development of CI-AKI following administration of the first contrast agent; 2) the time interval between the two procedures $(P=0.037)$, ACEI/ARB usage $(P=0.039)$, IABP usage $(P=0.040)$ and the occurrence of CI-AKI after the first procedure $(P=0.015)$ were independent predictors of CI-AKI following exposure to the second contrast agent; and 3) if the time interval between the two procedures was 3 days or less, then CI-AKI following the second contrast agent was more likely.

The main finding of the present study is the identification of several independent risk factors for CI-AKI in patients receiving a contrast agent twice within a short period of time. Some of the established risk factors have also been corroborated in our study, such as diuretics and IABP usage $[20,21]$. We found that IABP usage could also increase the incidence of CI-AKI after the second contrast agent. The reason for this finding may be similar to those reported in previous literature. Those findings mainly relate to the nature of intra-arterial injection, the high volume of the contrast, the patients' advanced age, and the severity of the patients' illness, such as a greater number of comorbid conditions, more advanced vascular disease, hypertension, and diabetes $[22$, 23].

The relationship between ACEI/ARB and CI-AKI is still controversial. Some investigators have pointed out that the use of ACEI/ARB may protect the kidneys against the effects of CI-AKI [24, 25]. Recently, Duan et al. [26] proposed that ACEIs can prevent CI-AKI. Nonetheless, opposing results have been published over the past few years. For example, Kiski et al. [27] found that patients taking ACEIs/ARBs developed CI-AKI significantly more often within $72 \mathrm{~h}$ after contrast media 
Table 1 Baseline patient characteristics in two groups

\begin{tabular}{|c|c|c|c|}
\hline Item & Group A $(n=559)$ & Group B $(n=48)$ & $P$ value \\
\hline Age (year, $x \pm s)$ & $60.2 \pm 11.0$ & $61.5 \pm 12.7$ & 0.438 \\
\hline Female $[n(\%)]$ & $121(21.6)$ & $14(29.1)$ & 0.229 \\
\hline Weight $(\mathrm{kg}, x \pm s)$ & $71.7 \pm 11.7$ & $72.1 \pm 11.7$ & 0.821 \\
\hline Height $(\mathrm{cm}, x \pm s)$ & $169.9 \pm 6.6$ & $170.3 \pm 6.7$ & 0.699 \\
\hline $\mathrm{BMI}\left(\mathrm{kg} / \mathrm{m}^{2}, x \pm s\right)$ & $24.8 \pm 3.6$ & $24.9 \pm 3.7$ & 0.930 \\
\hline Current smoker $[n(\%)]$ & $288(51.5)$ & $27(56.2)$ & 0.529 \\
\hline Current alcohol $[n(\%)]$ & $180(32.2)$ & $14(29.1)$ & 0.665 \\
\hline STEMI $[n(\%)]$ & $196(35.0)$ & $22(45.8)$ & 0.136 \\
\hline Hypertension [n(\%)] & $303(54.2)$ & $33(68.7)$ & 0.061 \\
\hline Diabetes $[n(\%)]$ & $132(23.6)$ & $16(33.3)$ & 0.132 \\
\hline CKD $[n(\%)]$ & $34(6.1)$ & $6(12.5)$ & 0.119 \\
\hline Stroke $[n(\%)]$ & $53(9.5)$ & $8(16.7)$ & 0.130 \\
\hline Cancer $[n(\%)]$ & $4(0.7)$ & 0 & 1.000 \\
\hline Peripheral vascular disease $[n(\%)]$ & $7(1.3)$ & $2(4.2)$ & 0.109 \\
\hline Ulcer $[n(\%)]$ & $58(10.4)$ & $4(8.3)$ & 0.807 \\
\hline NYHA class $\|-I I I[n(\%)]$ & 109 (19.5) & $15(31.3)$ & 0.053 \\
\hline $\mathrm{SBP}(\mathrm{mmHg}, x \pm s)$ & $133.9 \pm 21.9$ & $136.8 \pm 22.4$ & 0.379 \\
\hline $\mathrm{DBP}(\mathrm{mmHg}, x \pm s)$ & $79.3 \pm 13.4$ & $80.85 \pm 13.5$ & 0.426 \\
\hline HR (beat/min, $x \pm s)$ & $76.4 \pm 14.1$ & $81.4 \pm 17.3$ & 0.022 \\
\hline Basic-Scr $(\mu \mathrm{mol} / \mathrm{L}, x \pm s)$ & $77.4 \pm 25.0$ & $75.1 \pm 24.5$ & 0.548 \\
\hline Basic-eGFR $\left[\mathrm{ml} /\left(\min \bullet 1.73 \mathrm{~m}^{2}\right), x \pm s\right]$ & $108.4 \pm 41.5$ & $110.0 \pm 43.0$ & 0.908 \\
\hline $\mathrm{BUN}(\mathrm{mmol} / \mathrm{L}, x \pm s)$ & $5.9 \pm 1.9$ & $6.1 \pm 1.3$ & 0.638 \\
\hline $\mathrm{K}^{+}(\mathrm{mmol} / \mathrm{L}, x \pm s)$ & $4.1 \pm 0.4$ & $4.2 \pm 0.3$ & 0.243 \\
\hline $\mathrm{Na}^{+}(\mathrm{mmol} / \mathrm{L}, x \pm s)$ & $140.1 \pm 3.4$ & $139.6 \pm 3.0$ & 0.391 \\
\hline $\operatorname{PLT}\left(\times 10^{9} / \mathrm{L}, x \pm s\right)$ & $208.8 \pm 55.8$ & $209.5 \pm 55.4$ & 0.943 \\
\hline WBC $\left(\times 10^{9} / L, x \pm s\right)$ & $8.3 \pm 3.1$ & $8.3 \pm 2.8$ & 0.995 \\
\hline $\mathrm{Hb}(\mathrm{g} / \mathrm{L}, x \pm s)$ & $137.9 \pm 24.1$ & $136.2 \pm 17.4$ & 0.671 \\
\hline $\mathrm{TC}(\mathrm{mmol} / \mathrm{L}, x \pm s)$ & $4.2 \pm 1.3$ & $4.1 \pm 1.0$ & 0.819 \\
\hline $\mathrm{TG}\left[\mathrm{mmol} / \mathrm{L}, \mathrm{M}\left(\mathrm{Q}_{1}, \mathrm{Q}_{3}\right)\right]^{\mathrm{a}}$ & $1.48(1.13,1.72)$ & $1.44(0.72,1.98)$ & 0.367 \\
\hline $\operatorname{ALT}\left[\mathrm{mmol} / \mathrm{L}, \mathrm{M}\left(\mathrm{Q}_{1}, \mathrm{Q}_{3}\right)\right]^{\mathrm{a}}$ & $26.00(13,81)$ & $24.00(9,63)$ & 0.975 \\
\hline AST $\left[\mathrm{mmol} / \mathrm{L}, \mathrm{M}\left(\mathrm{Q}_{1}, \mathrm{Q}_{3}\right)\right]^{\mathrm{a}}$ & $25.00(7,76)$ & $23.00(4,67)$ & 0.250 \\
\hline ALB $(\mathrm{mmol} / \mathrm{L}, x \pm s)$ & $33.2 \pm 20.5$ & $35.3 \pm 15.5$ & 0.718 \\
\hline $\mathrm{HDL}-\mathrm{C}(\mathrm{mmol} / \mathrm{L}, x \pm s)$ & $1.2 \pm 0.4$ & $1.0 \pm 0.3$ & 0.684 \\
\hline LDL-C (mmol/L, $x \pm s)$ & $2.4 \pm 1.0$ & $2.4 \pm 0.9$ & 0.790 \\
\hline Glucose $(\mathrm{mmol} / \mathrm{L}, x \pm s)$ & $6.6 \pm 2.9$ & $7.2 \pm 3.4$ & 0.337 \\
\hline $\mathrm{CK}\left[\mathrm{U} / \mathrm{L}, \mathrm{M}\left(\mathrm{Q}_{1}, \mathrm{Q}_{3}\right)\right]^{\mathrm{a}}$ & $137.00(27.31,452.50)$ & $108.00(45.79,168.75)$ & 0.303 \\
\hline CK-MB $\left[U / L, M\left(Q_{1}, Q_{3}\right)\right]^{a}$ & $17.00(7.14,22.75)$ & $17.00(6.34,16.75)$ & 0.936 \\
\hline $\mathrm{TNT}\left[\mathrm{ng} / \mathrm{L}, \mathrm{M}\left(\mathrm{Q}_{1}, \mathrm{Q}_{3}\right)\right]^{\mathrm{a}}$ & $0.05(0.01,0.523)$ & $0.05(0.01,0.162)$ & 0.241 \\
\hline$N T$-proBNP $\left[\mu \mathrm{g} / \mathrm{L}, \mathrm{M}\left(\mathrm{Q}_{1}, \mathrm{Q}_{3}\right)\right]^{\mathrm{a}}$ & $83.00(12.00,1085.00)$ & $140.00(21.00,2050.00)$ & 0.236 \\
\hline $\mathrm{LV}(\mathrm{mm}, x \pm s)$ & $48.8 \pm 6.4$ & $49.8 \pm 5.8$ & 0.687 \\
\hline $\mathrm{EF}(\%, x \pm s)$ & $58.9 \pm 10.7$ & $57.6 \pm 11.6$ & 0.730 \\
\hline \multicolumn{4}{|l|}{ Medicine care $[n(\%)]$} \\
\hline Diuretics & $210(37.6)$ & $27(56.3)$ & 0.011 \\
\hline$C C B$ & $231(41.3)$ & $21(43.8)$ & 0.743 \\
\hline
\end{tabular}


Table 1 Baseline patient characteristics in two groups (Continued)

\begin{tabular}{llll}
\hline Item & Group A $(n=559)$ & Group B $(n=48)$ & $P$ value \\
\hline$\beta-$ RB & $469(83.9)$ & $40(83.3)$ & 0.918 \\
ACEI/ARB & $444(79.4)$ & $34(70.8)$ & 0.162 \\
Statins & $366(65.5)$ & $37(77.1)$ & 0.102 \\
Digitalis & $103(18.4)$ & $17(35.4)$ & 0.005
\end{tabular}

Group A No Cl-AKI from second agent, Group B Cl-AKI from second agent, BMI Body mass index, STEMI ST-segment elevation myocardial infarction, CKD Chronic kidney disease, NYHA New York Heart Association, SBP Systolic blood pressure, DBP Diastolic blood pressure, HR Heart rate, Scr Serum creatinine, eGFR Estimated glomerular filtration rate, BUN Blood urea nitrogen, PLT Platelets, WBC White blood cells, Hb Hemoglobin, TC Total cholesterol, TG Triglycerides, ALT Alanine aminotransferase, AST Aspartate aminotransferase, $A L B$ Albumin, HDL-C High-density lipoprotein cholesterol, $L D L-C$ Low-density lipoprotein cholesterol, $C K$ Creatine kinase, $C K-M B$ Creatine kinase-myocardial band, TNT Troponin T, NT-proBNP N-terminal pro-brain natriuretic peptide, $L V$ Left ventricular, EF Ejection fraction, CCB Calcium channel blocker, $\beta$-RB $\beta$-receptor blocker, $A C E I$ Angiotensin-converting enzyme inhibitor, ARB Angiotensin II receptor antagonist

${ }^{a}$ Means nonnormally distributed continuous variables

administration. This observation is consistent with our results, which showed that the use of ACEIs/ARBs was associated with an increased incidence of CI-AKI following exposure to the second contrast agent.

We also found that if patients developed CI-AKI following the first procedure, then they were more likely to develop CI-AKI after the second procedure. It is well known that the mechanism of CI-AKI is mainly caused by the toxic properties of the contrast media, such as osmolality, viscosity, and ionic strength. The cytotoxicity of contrast agents is probably caused by iodine and leads to apoptosis and cell death of both endothelial and tubular cells [28]. Therefore, in patients who have recently developed one episode of CI-AKI, contrast toxicity and other factors may affect kidney function, increasing the likelihood of more frequent episodes of CI-AKI following the second exposure.

In the present study, we newly identified that the time interval between two exposures to contrast agents is an independent predictor of CI-AKI following the second procedure. Further analysis showed that the incidence of CI-AKI during the second perioperative period was significantly higher if the second exposure occurred within 3 days rather than 4-6 days or $\geq 7$ days. In the 2015 ESC congress, Park et al. [29] reported a similar result when evaluating the safe time interval between exposure to multidetector computed tomography (MDCT) and coronary

Table 2 Agent procedural characteristics in two groups

\begin{tabular}{|c|c|c|c|}
\hline Item & Group A $(n=559)$ & Group B $(n=48)$ & $P$ value \\
\hline \multicolumn{4}{|l|}{ TRI $[n(\%)]$} \\
\hline TRI in first agent & $426(76.2)$ & $34(70.8)$ & 0.404 \\
\hline TRI in second agent & $433(77.5)$ & $35(72.9)$ & 0.472 \\
\hline Agents interval time $\left[\mathrm{d}, \mathrm{M}\left(\mathrm{Q}_{1}, \mathrm{Q}_{3}\right)\right]^{\mathrm{a}}$ & $5(3,8)$ & $4(3,6)$ & 0.218 \\
\hline $\mathrm{CV}$ in 1st agent $\left[\mathrm{ml}, \mathrm{M}\left(\mathrm{Q}_{1}, \mathrm{Q}_{3}\right)\right]^{\mathrm{a}}$ & $100.00(40.00,140.00)$ & $90.00(50.00,75.00)$ & 0.128 \\
\hline $\mathrm{CV}$ in 2 nd agent $\left[\mathrm{ml}, \mathrm{M}\left(\mathrm{Q}_{1}, \mathrm{Q}_{3}\right)\right]^{\mathrm{a}}$ & $150.00(50.00,100.00)$ & $150.00(50.00,100.00)$ & 0.334 \\
\hline Number of stent $(x \pm s)$ & $2.23 \pm 1.58$ & $1.82 \pm 1.19$ & 0.096 \\
\hline Multivessel disease $[n(\%)]$ & $392(70.1)$ & $37(77.1)$ & 0.310 \\
\hline LM lesion [n(\%)] & $11(1.9)$ & $3(6.3)$ & 0.091 \\
\hline Basic SYNTAX score $(x \pm s)$ & $17.2 \pm 7.5$ & $19.2 \pm 8.4$ & 0.082 \\
\hline Residual SYNTAX score $(x \pm s)$ & $8.8 \pm 5.8$ & $11.1 \pm 7.0$ & 0.073 \\
\hline Complete revascularization [n(\%)] & $353(63.2)$ & $24(50.0)$ & 0.072 \\
\hline Cl-AKI post-first agent $[n(\%)]$ & $41(7.3)$ & $15(31.3)$ & $<0.001$ \\
\hline \multicolumn{4}{|l|}{ Serum creatinine $(\mu \mathrm{mol} / \mathrm{L}, x \pm s)$} \\
\hline Baseline & $77.4 \pm 25.0$ & $75.1 \pm 24.5$ & 0.548 \\
\hline Maximal post-first agent & $84.1 \pm 33.9$ & $93.7 \pm 39.4$ & 0.094 \\
\hline Pre-second agent & $84.4 \pm 56.6$ & $81.3 \pm 24.6$ & 0.729 \\
\hline Maximal post-second agent & $76.6 \pm 27.7$ & $100.1 \pm 27.3$ & $<0.001$ \\
\hline
\end{tabular}

Group A No Cl-AKI from second agent, Group B Cl-AKI from second agent, TRI Trans-radial intervention, CV Contrast volume, LM Left main, SYNTAX Synergy between percutaneous coronary intervention with Taxus and cardiac surgery

${ }^{a}$ Means non-normally distributed continuous variables 
Table 3 Regression analysis for $\mathrm{Cl}$-AKI predictors of the first agent

\begin{tabular}{|c|c|c|c|c|}
\hline \multirow[t]{2}{*}{ Variable } & \multirow{2}{*}{$\begin{array}{l}\text { Univariate analysis } \\
P \text { value }\end{array}$} & \multicolumn{3}{|c|}{ Multivariate analysis } \\
\hline & & $O R$ & $95 \% \mathrm{Cl}$ & $P$ value \\
\hline Female & 0.854 & 1.026 & $0.424-2.484$ & 0.954 \\
\hline NYHA Class II-III & 0.004 & 1.326 & $0.542-3.248$ & 0.536 \\
\hline Hypertension & 0.626 & 1.671 & $0.736-3.796$ & 0.220 \\
\hline Diabetes & 0.276 & 1.179 & $0.483-2.876$ & 0.718 \\
\hline Diuretics & $<0.001$ & 3.761 & $1.462-9.675$ & 0.006 \\
\hline CCB & 0.228 & 0.269 & $0.086-1.838$ & 0.240 \\
\hline$\beta-R B$ & 0.715 & 0.399 & $0.157-1.011$ & 0.053 \\
\hline ACEI/ARB & 0.757 & 0.575 & $0.240-1.377$ & 0.214 \\
\hline Statins & 0.518 & 0.643 & $0.097-3.304$ & 0.390 \\
\hline Digitalis & 0.010 & 1.588 & $0.608-4.149$ & 0.345 \\
\hline IABP & $<0.001$ & 4.245 & $1.378-13.083$ & 0.012 \\
\hline LM lesion & 0.716 & 0.564 & $0.256-1.241$ & 0.155 \\
\hline Age & 0.381 & 1.000 & $0.965-1.035$ & 0.983 \\
\hline Basic SYNTAX score & 0.078 & 0.996 & $0.946-1.047$ & 0.861 \\
\hline
\end{tabular}

NYHA New York Heart Association, CCB Calcium channel blocker, $\beta$-RB $\beta$-receptor blocker, ACEI Angiotensin-converting enzyme inhibitor, ARB Angiotensin II receptor antagonist, IABP Intra-aortic balloon pump, LM Left main, SYNTAX Synergy between percutaneous coronary intervention with Taxus and cardiac surgery

revascularization regarding the risk of CI-AKI. Their study pointed out that CI-AKI was more frequent in the earlier time interval in the PCI group. Furthermore, multivariate analysis identified a short interval between MDCT and PCI as a unique independent predictor of CI-AKI ( $\leq 2$ days vs. $>14$ days: $H R=2.37$, 95\% CI: $1.105-5.098, P=0.018 ; 3-14$ days vs. $>14$ days: $H R=2.07,95 \%$ CI: $0.960-4.445, \quad P=0.064$ ). Some articles have reported that serum creatinine will usually peak $2-3$ days following injection of a contrast agent and then slowly return to baseline within 14 days $[30,31]$. Our result may have been because a repeat injection of contrast agent within 3 days $(72 \mathrm{~h})$ of the first exposure occurred at the time of peak renal

Table 4 Regression analysis for Cl-AKI predictors after second agent

\begin{tabular}{|c|c|c|c|c|}
\hline \multirow[t]{2}{*}{ Variable } & \multirow{2}{*}{$\begin{array}{l}\text { Univariate analysis } \\
P \text { value }\end{array}$} & \multicolumn{3}{|c|}{ Multivariate analysis } \\
\hline & & $\overline{O R}$ & $95 \% \mathrm{Cl}$ & $P$ value \\
\hline Interval time & 0.033 & 1.170 & $1.980-2.370$ & 0.037 \\
\hline Female & 0.232 & 1.460 & $0.660-3.226$ & 0.350 \\
\hline NYHA class II-III & 0.056 & 1.381 & $0.576-3.309$ & 0.469 \\
\hline Hypertension & 0.064 & 2.107 & $0.929-4.774$ & 0.074 \\
\hline Diabetes & 0.135 & 1.296 & $0.582-2.888$ & 0.526 \\
\hline Diuretics & 0.012 & 1.268 & $0.489-3.288$ & 0.625 \\
\hline$C C B$ & 0.743 & 1.329 & $0.601-2.939$ & 0.482 \\
\hline$\beta-R B$ & 0.918 & 0.698 & $0.277-1.759$ & 0.446 \\
\hline ACEI/ARB & 0.166 & 0.428 & $0.191-0.958$ & 0.039 \\
\hline Statins & 0.106 & 4.203 & $0.809-21.846$ & 0.088 \\
\hline Digitalis & 0.006 & 1.291 & $0.453-3.677$ & 0.632 \\
\hline IABP & 0.001 & 3.302 & $1.055-10.335$ & 0.040 \\
\hline LM lesion & 0.164 & 0.880 & $0.356-2.177$ & 0.782 \\
\hline Age & 0.438 & 0.996 & $0.963-1.031$ & 0.838 \\
\hline Basic SYNTAX score & 0.083 & 1.006 & $0.952-1.063$ & 0.838 \\
\hline CI-AKI post-first agent & $<0.001$ & 3.454 & $1.278-9.333$ & 0.015 \\
\hline
\end{tabular}

NYHA New York Heart Association, CCB Calcium channel blocker, $\beta$-RB $\beta$-receptor blocker, ACEI Angiotensin-converting enzyme inhibitor, ARB Angiotensin II receptor antagonist, IABP Intra-aortic balloon pump, LM Left main, SYNTAX Synergy between percutaneous coronary intervention with Taxus and cardiac surgery, CI-AKI Contrast-induced acute kidney injury 


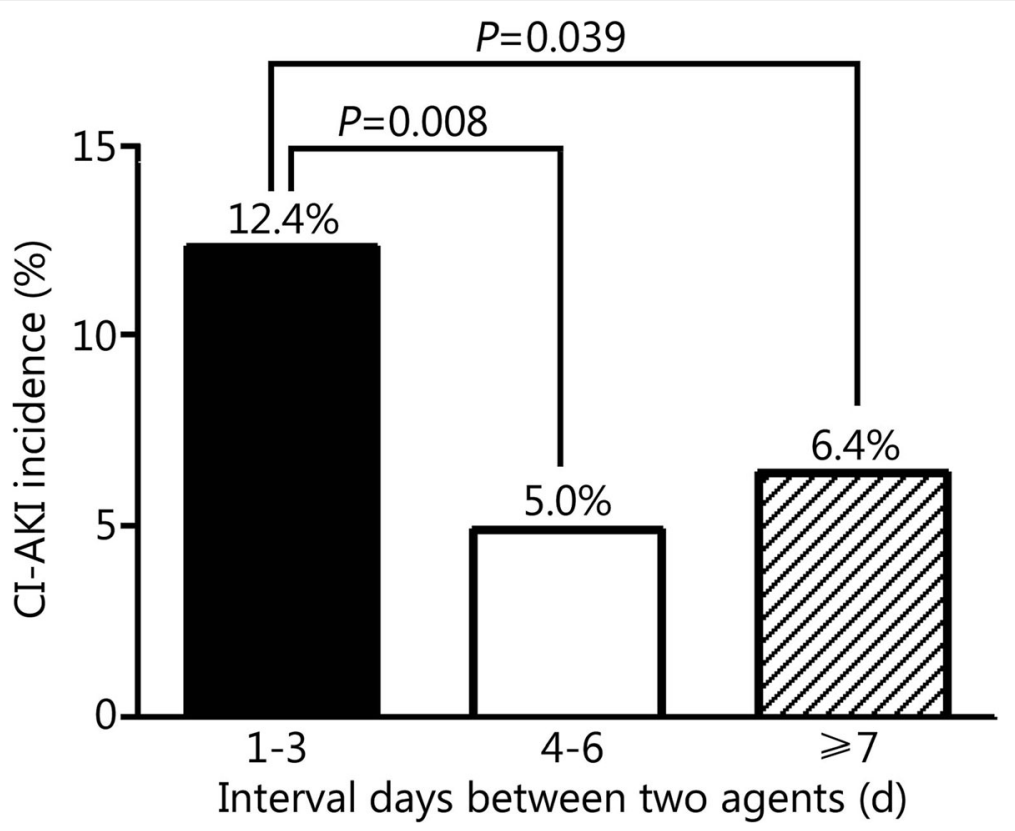

Fig. $1 \mathrm{Cl}$-AKI occurrence after the 2nd agent by tertile of the interval between the two contrast agent exposures

toxicity caused by the previous agent. Therefore, such a strategy of repeat procedures may expose kidneys to a higher risk of CI-AKI.

Other factors, such as diabetes and left main coronary artery lesions, have been reported to be strong risk factors for CI-AKI in previous studies [2, 32]. Though the results of our multivariate analysis did not find similar correlations, trends were evident for several of these factors. In addition, the lack of significant associations may be related to the small sample size of group B.

Recent studies have demonstrated that for patients who develop CI-AKI following exposure to a contrast agent, the in-hospital and long-term adverse clinical outcomes can be attributed to cardiovascular instability and the resulting complications $[2,5,33]$. In our study, the clinical adverse events were more numerous for patients who developed CI-AKI after the second contrast agent. These findings seem to be consistent with those of previous studies [34, 35]. However, patients who developed
CI-AKI after the second contrast agent did not have a significantly worse clinical prognosis during the followup period. This finding might be explained by the fact that some patients in group A developed CI-AKI after the first agent, while some in group B did not, which could have affected the results. The small sample size of patients receiving contrast media twice may also have impacted death or MACE incidence in this study.

Our study has several limitations. First, this study used a nonrandomized, retrospective, single-center design, which may have significantly affected the results due to confounding factors. Second, we excluded some patients whose information regarding contrast media usage and serum creatinine levels during the procedures was lost, which could potentially result in serious selection bias. Additionally, atrial fibrillation has been notoriously recognized as a predictor of poor prognostic outcomes, but we have not analyzed arrythmia types such as atrial fibrillation or any others. We have added this to the limitation section, and will analyze arrythmia in future papers

Table 5 Clinical follow-up after contrast medium administration [n(\%)]

\begin{tabular}{llll}
\hline Variable & Group A $(n=559)$ & Group B $(n=48)$ & $P$ value \\
\hline All cause death & $21(3.8)$ & $3(4.2)$ & 0.426 \\
MACE & $51(9.1)$ & $6(12.5)$ & 0.438 \\
$\quad$ Cardiac death & $19(3.4)$ & $3(4.2)$ & 0.154 \\
Myocardial infarction & $3(0.5)$ & 0 & 1.000 \\
In-stent restenosis & $28(5.0)$ & $3(6.3)$ & 0.728 \\
Stent thrombosis & $1(0.2)$ & 0 & 1.000 \\
\hline
\end{tabular}

Group A No Cl-AKI from 2nd agent, Group B Cl-AKI from 2nd agent, MACE Major Adverse Cardiovascular Events 


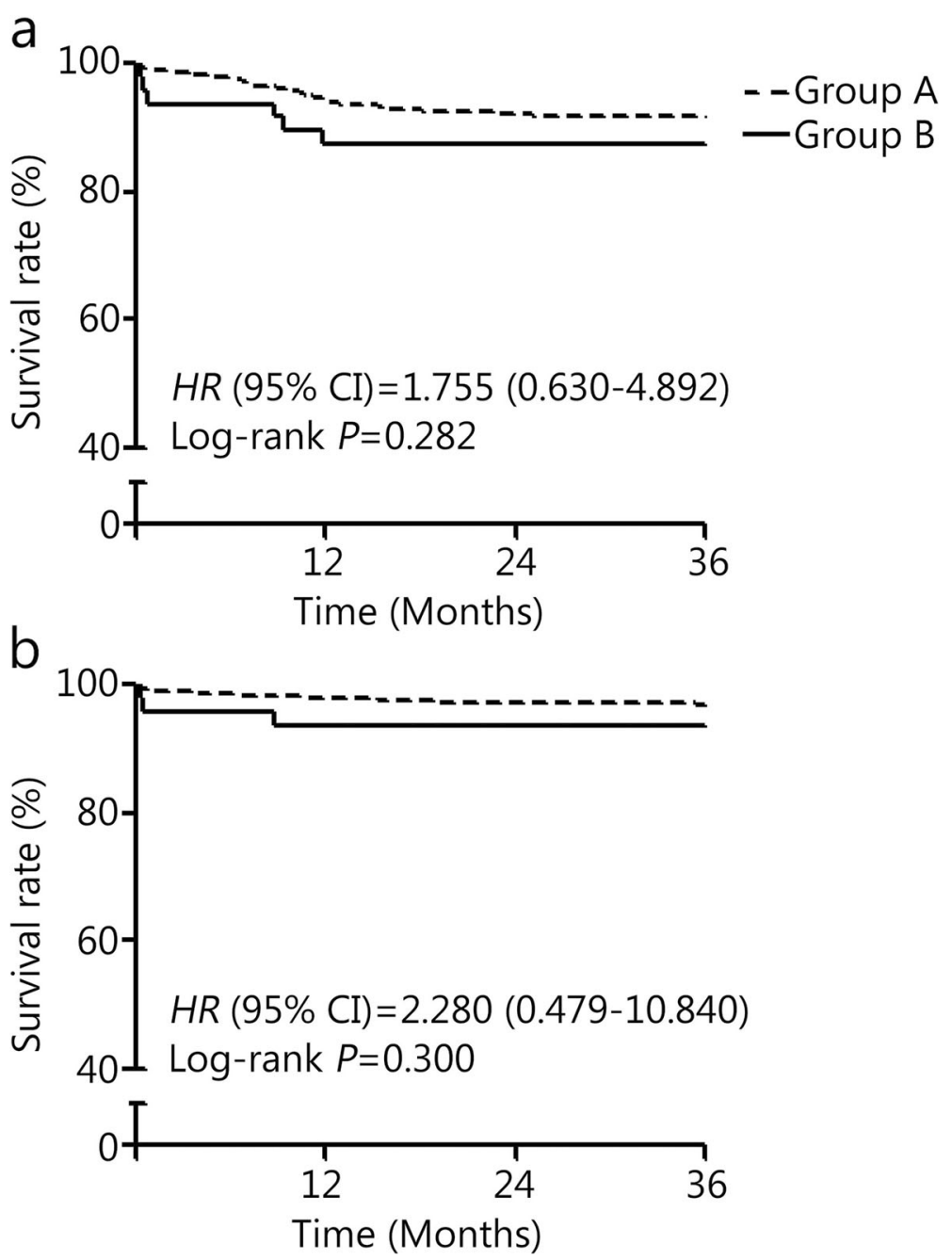

Fig. 2 Free survival analysis from MACE (a) and all-cause death (b)

[36]. Finally, in the receiver operator characteristic curve analysis, our cut-off value for predicting the development of CI-AKI in patients who received a contrast agent twice within 30 days had a slightly low sensitivity. This may be caused by the small sample size. Nevertheless, our multivariate analysis showed that the time interval between administration of the two contrast agents was one of the major predictors for developing CI-AKI, even after adjusting for various confounding factors. Further multicenter, large-scale and randomized studies may be needed to confirm this observation.

\section{Conclusions}

In conclusion, there are several major predictors of CIAKI in patients who receive a contrast agent twice within 30 days. Diuretic and IABP usage are independent predictors of CI-AKI following exposure to the first contrast agent. The major predictors of CI-AKI after the second contrast agent are the time interval between exposures, ACEI/ARB usage, and IABP usage. Furthermore, if the interval between two procedures is 3 days or less, then CI-AKI following the second administration of a contrast agent is more likely.

\section{Abbreviations}

ACS: Acute coronary syndrome; ACEl: Angiotensin-converting enzyme inhibitor; ALB: Albumin; ALT: Alanine aminotransferase; ARB: Angiotensin II receptor antagonist; AST: Aspartate aminotransferase; BMI: Body mass index; $\beta$-RB: $\beta$-receptor blocker; BUN: Blood urea nitrogen; CAD: Coronary artery disease; CAG: Coronary angiography; CCB: Calcium channel blocker; CIAKI: Contrast-induced acute kidney injury; CK: Creatine kinase; CKD: Chronic kidney disease; CK-MB: Creatine kinase-myocardial band; CS: Cardiogenic shock; CV: Contrast volume; DBP: Diastolic blood pressure;

ECG: Electrocardiogram; EF: Ejection fraction; eGFR: Estimated glomerular filtration rate; Hb: Hemoglobin; HDL-C: High-density lipoprotein cholesterol; HR: Heart rate; IABP: Intra-aortic balloon pump; LDL-C: Low-density lipoprotein cholesterol; LM: Left main; LV: Left ventricular; MACE: Major adverse cardiovascular events; MDCT: Multidetector computed tomography; NT-proBNP: N-terminal pro-brain natriuretic peptide; NYHA: New York Heart Association; PCl: Percutaneous coronary intervention; PLT: Platelets; SBP: Systolic blood pressure; Scr: Serum creatinine; STEMI: ST-segment elevation myocardial infarction; SYNTAX: Synergy between percutaneous coronary intervention with Taxus and cardiac surgery; TC: Total cholesterol; 
TG: Triglycerides; TNT: Troponin T; TRI: Trans-radial intervention; WBC: White blood cells

\section{Acknowledgements}

The authors are grateful to the subjects who participated in the study and to the physicians' assistance in this study.

\section{Meeting presentation}

The material has not otherwise been presented or published.

\section{Disclaimer}

The views expressed in this article are those of the authors and do not necessarily reflect the official policy or position of General Hospital of Shenyang Military Region, the Department of China Government. Discussion or mention of any commercial products or vendor names within this presentation does not create or imply any China endorsement.

\section{Authors' contributions}

XZW, QMJ and XZ performed the patient surgeries. XZ and YLH participated in the design of the study. CHG, LLR, YZ, and JYP carried out the statistical analysis. XZ collected the data. CHG participated in the design and coordination and helped to draft the manuscript. All authors read and approved the final manuscript.

\section{Funding}

Chinese Medical Doctor Association Discovery-Fund Project, Grant/Award Number (DFCMDA201417); National Basic Research Program of China, Grant/ Award Number (2012CB517804).

\section{Availability of data and materials}

The datasets used and/or analyzed during the current study are not publicly available. Access from the corresponding author's institution can be requested by completion and approval of a Data Sharing Agreement Application.

\section{Ethics approval and consent to participate}

All patients or their relatives provided informed consent, and the study was approved by the ethical committee of General Hospital of Shenyang Military Region.

\section{Consent for publication}

All authors consent to publication in Military Medical Research.

\section{Competing interests}

The authors declare that they have no competing interests.

\section{Author details}

${ }^{1}$ Cardiovascular Research Institute and Department of Cardiology, General Hospital of Shenyang Military Region, Shenyang 110840, China. ${ }^{2}$ Department of Cardiovascular, Anqing Municipal Hospital, Anqing 246000, Anhui, China.

\section{Received: 15 July 2019 Accepted: 16 March 2020}

Published online: 26 March 2020

\section{References}

1. McCullough PA. Contrast-induced acute kidney injury. J Am Coll Cardiol. 2008:51(15):1419-28.

2. Rihal CS, Textor SC, Grill DE, Berger PB, Ting HH, Best PJ, et al. Incidence and prognostic importance of acute renal failure after percutaneous coronary intervention. Circulation. 2002;105(19):2259-64.

3. Nash K, Hafeez A, Hou S. Hospital-acquired renal insufficiency. Am J Kidney Dis. 2002:39:930-6.

4. Sadeghi HM, Stone GW, Grines CL, Mehran R, Dixon SR, Lansky AJ, et al. Impact of renal insufficiency in patients undergoing primary angioplasty for acute myocardial infarction. Circulation. 2003;108:2769-75.

5. Marenzi G, Lauri G, Assanelli E, Campodonico J, De Metrio M, Marana I, et al. Contrast-induced nephropathy in patients undergoing primary angioplasty for acute myocardial infarction. J Am Coll Cardiol. 2004;44:1780-5.

6. Solomon RJ, Natarajan MK, Doucet S, Sharma SK, Staniloae CS, Katholi RE, et al. Cardiac angiography in renally impaired patients (CARE) study: a radomized double-blind trail of contrast-induced nephropathy in patients with chronic kidney disease. Circulation. 2007:115:3189-96.

7. Mehran R, Aymong ED, Nikolsky E, Lasic Z, lakovou I, Fahy M, et al. A simple risk score for prediction of contrast-induced nephropathy after percutaneous coronary intervention: development and initial validation. J Am Coll Cardiol. 2004:44:1393-9.

8. Wi J, Ko YG, Kim JS, Kim BK, Choi D, Ha JW, et al. Impact of contrast-induced acute kidney injury with transient or persistent renal dysfunction on longterm outcomes of patients with acute myocardial infarction undergoing percutaneous coronary intervention. Heart. 2011;97:1753-7.

9. Wickenbrock I, Perings C, Maagh P, Quack I, van Bracht M, Prull MW, et al. Contrast medium induced nephropathy in patients undergoing percutaneous coronary intervention for acute coronary syndrome: differences in STEMI and NSTEMI. Clin Res Cardiol. 2009;98:765-72.

10. Pyxaras SA, Sinagra G, Mangiacapra F, Perkan A, Di Serafino L, Vitrella G, et al. Contrast-induced nephropathy in patients undergoing primary percutaneous coronary intervention without acute left ventricular ejection fraction impairment. Am J Cardiol. 2013;111:684-8.

11. Solomon R, Dauerman HL. Contrast-induced acute kidney injury. Circulation. 2010;122:2451-5.

12. Seeliger $E$, Sendeski M, Rihal CS, Persson PB. Contrast-induced kidney injury: mechanisms, risk factors, and prevention. Eur Heart J. 2012;33:2007-15.

13. Mehta RL, Kellum JA, Shah SV, Molitoris BA, Ronco C, Warnock DG, et al. Acute kidney injury network: report of an initiative to improve outcomes in acute kidney injury. Crit Care. 2007;11:R31.

14. Bellomo R, Ronco C, Kellum JA, Mehta RL, Palevsky P, Acute Dialysis Quality Initiative workgroup. Acute renal failure - definition, outcome measures, animal models, fluid therapy and information technology needs: the Second International Consensus Conference of the Acute Dialysis Quality Initiative (ADQI) group. Crit Care. 2004;8(4):R204-12.

15. Alessandri N, Lanzi L, Garante CM, Tersigni F, Sergiacomi R, Petrassi M, et al. Prevention of acute renal failure postcontrast imaging in cardiology: a randomized study. Eur Rev Med Pharmacol Sci. 2013;17(Suppl 1):13-21.

16. National Kidney Foundation. K/DOQI clinical practice guidelines for chronic kidney disease: evaluation, classification, and stratification. Am J Kidney Dis. 2002:39(2 Suppl 1):S1-266.

17. Thygesen K, Alpert JS, Jaffe AS, Simoons ML, Chaitman BR, White HD, et al. Third universal definition of myocardial infarction. J Am Coll Cardiol. 2012; 60(16):1581-98.

18. World Health Organization, Regional Office for South-East Asia. Prevention of iron deficiency anaemia in adolescents. WHO Regional Office for SouthEast Asia. 2011. https://apps.who.int/iris/handle/10665/205656.

19. Ibanez B, James S, Agewall S, Antunes MJ, Bucciarelli-Ducci C, Bueno H, et al. 2017 ESC guidelines for the management of acute myocardial infarction in patients presenting with ST-segment elevation: the task force for the management of acute myocardial infarction in patients presenting with ST-segment elevation of the European Society of Cardiology (ESC). Eur Heart J. 2018;39(2):119-77.

20. Ejaz AA, Mohandas R. Are diuretics harmful in the management of acute kidney injury? Curr Opin Nephrol Hypertens. 2014;23(2):155-60.

21. Solomon R. Contrast-induced acute kidney injury: is there a risk after intravenous contrast? Clin J Am Soc Nephrol. 2008;3(5):1242-3.

22. Mehran R, Nikolsky E. Contrast-induced nephropathy: definition, epidemiology, and patients at risk. Kidney Int. 2006;69:S11-5.

23. Fuiano G, Mancuso D, Indolfi C, Mongiardo A, Sabbatini M, Conte G, et al. Early detection of progressive renal dysfunction in patients with coronary artery disease. Kidney Int. 2005;68(6):2773-80.

24. Gupta RK, Kapoor A, Tewari S, Sinha N, Sharma RK. Captopril for preventing of contrast-induced nephropathy in diabetic patients: a randomized study. Indian Heart J. 1999:51:521-6.

25. Hashemi M, Kharazi A, Shahidi S. Captopril for prevention of contrast induced nephropathy in patients undergoing coronary angioplasty: a double blind placebo controlled clinical trial. J Res Med Sci. 2005;10(5):3058.

26. Duan $\mathrm{SB}$, Wang YH, Liu FY, Xu XQ, Wang $P$, Zou Q, et al. The protective role of telmisartan against nephrotoxicity induced by $\mathrm{X}$-ray contrast media in rat model. Acta Radiol. 2009;50(7):754-9.

27. Kiski D, Stepper W, Brand E, Breithardt G, Reinecke H. Impact of reninangiotensin-aldosterone blockade by angiotensin-converting enzyme inhibitors or AT-1 blockers on frequency of contrast medium-induced 
nephropathy: a post-hoc analysis from the Dialysis-versus-Diuresis (DVD) trial. Nephrol Dial Transplant. 2010;25(3):759-64.

28. Sendeski MM. Pathophysiology of renal tissue damage by iodinated contrast media. Clin Exp Pharmacol Physiol. 2011:38(5):292-9.

29. Park JH, Yoon HJ, Won KB, Cho YK, Park HS, Kim HS, et al. Increased risk of contrast induced nephropathy in consecutive percutaneous coronary intervention after multidetector computed tomography within short interval. Eur Heart J. 2015;36:38.

30. Waybill M, Waybill P. Contrast media-induced nephrotoxicity: identification of patients at risk and algorithms for prevention. J Vasc Interv Radiol. 2001; 12(1):3-9.

31. Owen RJ, Hiremath S, Myers A, Fraser-Hill M, Barrett BJ. Canadian Association of Radiologists consensus guidelines for the prevention of contrast-induced nephropathy: update 2012. Can Assoc Radiol J. 2014;65(2): 96-105.

32. Kim JH, Yang JH, Choi SH, Song YB, Hahn JY, Choi JH, et al. Predictors of outcomes of contrast-induced acute kidney injury after percutaneous coronary intervention in patients with chronic kidney disease. Am J Cardiol. 2014;114(12):1830-5.

33. Senoo T, Motohiro M, Kamihata $H$, Yamamoto $S$, Isono $T$, Manabe $K$, et al. Contrast-induced nephropathy in patients undergoing emergency percutaneous coronary intervention for acute coronary syndrome. Am J Cardiol. 2010;105(5):624-8.

34. Bartholomew BA, Harjai KJ, Dukkipati S, Boura JA, Yerkey MW, Glazier S, et al. Impact of nephropathy after percutaneous coronary intervention and a method for risk stratification. Am J Cardiol. 2004:93(12):1515-9.

35. Goldberg A, Hammerman H, Petcherski S, Zdorovyak A, Yalonetsky S, Kapeliovich M, et al. Inhospital and 1-year mortality of patients who develop worsening renal function following acute ST-elevation myocardial infarction. Am Heart J. 2005;150(2):330-7.

36. Prasitlumkum N, Kanitsoraphan C, Kittipibul V, Rattanawong P, Chongsathidkiet $\mathrm{P}$, Cheungpasitporn W, et al. Baseline atrial fibrillation is associated with contrast-induced nephropathy after cardiac catheterization in coronary artery disease: systemic review and meta-analysis. Clin Cardiol. 2018;41(12):1555-62

Ready to submit your research? Choose BMC and benefit from:

- fast, convenient online submission

- thorough peer review by experienced researchers in your field

- rapid publication on acceptance

- support for research data, including large and complex data types

- gold Open Access which fosters wider collaboration and increased citations

- maximum visibility for your research: over $100 \mathrm{M}$ website views per year

At $\mathrm{BMC}$, research is always in progress.

Learn more biomedcentral.com/submissions 